\title{
An Insider Viewpoint on Cultural Norms for Marriage and Mate Selection Relevant to Immigration Fraud Detection in South Asian International Arranged Marriages
}

\author{
Noorfarah Merali \\ University of Alberta \\ noorfarah.merali@ualberta.ca
}

\begin{abstract}
South Asian immigrant families residing in Canada often seek spouses for their children from their home countries, and file applications to enable the foreign spouses to immigrate. Marriages of convenience for immigration pose a major threat to genuine international unions, as immigration officers evaluating marriage-based immigration applications must rule out fraudulent relations. Through focus groups with 27 cultural insiders, including South Asian religious and community leaders, this study identified subculture norms for marriage and mate selection that can directly inform immigration fraud detection: (a) intra-familial marriage practices among Pakistani Muslims and South Indians, (b) extra-familial marriage traditions among Hindus and Sikhs, and (c) exceptions to norms for widows and intergroup marriages. Implications for cultural education for immigration officers are discussed.
\end{abstract}

\section{Introduction}

Arranged marriage is a long-standing historical tradition among the diverse peoples of South Asia, which include Hindus, Muslims, and Sikhs from India, Pakistan, and the surrounding areas of Bangladesh, Nepal, and Sri Lanka (Assanand, Dias, Richardson, \& Waxler-Morrison, 1990; Ibrahim, Ohnishi, and Sandu, 1997). This cultural custom involves collaboration of parents and relatives to identify suitable marriage partners for their sons or daughters. Marriages are arranged based on the parents' perception of compatibility between the two individuals in culture, religion, social class or caste, family background, appearance, and personal character (Almeida, 1996; Assanand et al., 1990; Bhopal, 1999). Three subtypes of arranged marriage have been described in the literature, involving different levels of involvement and interaction among prospective marital partners and their families (Qureshi, 1991; Stopes-Roe \& Cochrane, 1990). The first subtype is the traditional or planned pattern. In this form of arranged marriage, parents identify, screen, and select a mate for their son or daughter through contact with relatives, family friends, or religious mediators. There may be little or no interaction between the identified marriage partners prior to the marriage ceremony ("blind marriage"), or one to two face-to-face meetings supervised by family members. The second subtype of arranged marriage is the modified traditional or delegation pattern. In this form of arranged marriage, the son or daughter plays a minor role in the selection of a mate by providing some input about the qualities or characteristics of a desirable mate from his/her perspective. Parents take into account this input in identifying a suitable marriage partner and may allow some independent interactions between the couple prior to planning the marriage ceremony. The last subtype of arranged marriage is the cooperative/joint-venture pattern. Both parents and their son or daughter may be involved in the identification, screening, and marriage planning process. Some dating and courtship may occur prior to the marriage and may be supervised or unsupervised (Qureshi, 1991; Stopes-Roe \& Cochrane, 1990).

Globalization has led to the dispersion of South Asians across several different continents, including Canada, bringing with them their unique cultural traditions. They are currently the largest visible minority group in Canada, with a population of 1.3 million people (Statistics Canada, 2006). The South Asian population grew 38 percent since the last national Census in 2001, with members of

Cultural and Pedagogical Inquiry, 2014, 6(2), pp. 4-16

ISSN 1916-3460 @ 2014 University of Alberta

http://ejournals.library.ualberta.ca/index.php/cpi/index 
this cultural group now representing one-quarter of all visible minorities (Statistics Canada, 2006). Canada's Multiculturalism Policy encourages cultural heterogeneity within the confines of linguistic duality (Berry, 2001, 2006); immigrants are encouraged to retain their ethnic heritage to enrich the character of Canadian society, but are expected to integrate into the surrounding milieu by acquiring one of Canada's official languages. This policy promotes intergroup tolerance and acceptance, and emphasizes immigrants' freedom of religion, belief, thought, expression, and tradition (Berry, 2001). In their research study, Kwak and Berry (2001) compared the acculturation patterns of South Asian immigrants in Canada with other Asian immigrant groups. South Asian parents and young adults were found to show the highest levels of maintenance of their cultural identity, family values, and traditional customs after immigration. The retention of the culture of origin was most pronounced in relation to customs surrounding marriage (Kwak \& Berry, 2001).

In the past decade, the South Asian arranged marriage custom has increasingly been applied across international borders, with families in Canada seeking partners for their children from their home countries (Kumar \& Srivastava, 2005). There are presently global factors that are prompting the practice of arranged marriage to take place across international borders: Preferences for male children have been evident in South Asian countries for years, with international attention being devoted to abolishing the major problem of female infanticide (United Nations Population Fund, 2007). The World Bank's (2012) World Development Report - Gender and Equality and Development indicated that over 250,000 girls were missing at birth in India. With the advent of technology allowing for the screening of gender of the fetus in this world region, the problem of male preferences has worsened due to frequent sex-selective abortions (World Bank, 2012). The present gender ratio is around 120 boys born for every 100 girls, but as dramatically imbalanced as 130 boys to every 100 girls in some villages (United Nations Population Fund, 2007; World Bank, 2012). Pakistan is another South Asian country where preferences for male children are apparent, but with less severely unbalanced gender ratios (World Bank, 2012).

Since the South Asian culture is characterized by a collectivist orientation that highly values family life and childrearing, families of males are often inclined to negotiate with families in Canada to seek women to account for local bride shortages. While it appears that families of foreign males may seek Canadian female marriage partners for them due to local bride shortages, existing research suggests that families of foreign females living in countries in South Asia that don't have bride shortages are often contacted by families from North America wanting traditional women for their sons (Raj \& Silverman, 2002). So, it appears that there are different "push" and "pull" factors that drive men and women to seek marriage partners from abroad.

After going back to South Asia to get married, the South Asian Canadian marriage partner subsequently returns to Canada and files a sponsorship application to enable the spouse to join him/her on Canadian soil (Kumar \& Srivastava, 2005). The most recently available national immigration statistics indicate that from the years 2003 to 2012, between 33,922 to 39,855 Canadians sought marriage partners from abroad each year. India and Pakistan were among the top source countries for spouses being sponsored from abroad, accounting for close to $50 \%$ of immigration in this category (Citizenship and Immigration Canada, 2012a).

When a Canadian marries someone living abroad, the marriage usually takes place in the foreign country and is required to conform to the laws of the nations of residence of both spouses. After the marriage, the North American partner returns home to file a sponsorship application to facilitate the foreign national's migration, so the couple can be re-united (Citizenship and Immigration Canada, 2002). Since marriage is the easiest way for foreigners to gain immigration rights, the Canadian government has expressed serious concerns about the abuse of our immigration system through marriages of convenience (Citizenship and Immigration Canada, 2011, 2012b). Entering a marriage for 
immigration purposes and then dissolving the relationship after landing in Canada is referred to as Marriage Fraud, and Canadian data suggests that $16 \%$ of cases of overseas marriage applications are fraudulent, or approximately 10,000 cases per year (Citizenship and Immigration Canada, 2012c). Therefore, immigration officers do a careful relationship assessment for each marriage-based immigration application to rule out fraudulent relations. Several issues are evaluated in this assessment including members of the couple's mutual commitment to a shared life, the exclusivity of their relationship, their level of physical, emotional, and financial interdependence, the permanence of their relations, and their presentation of themselves as a couple to their friends and cultural community (Citizenship and Immigration Canada, 2006). Types of evidence considered in these evaluations include the amount of pre-marital and post-marital contact among the couple as indicated by cohabitation, long-distance phone bills, documentation showing travel together, photographs of the couple over time, knowledge about one another and each other's families, joint bank accounts and assets, etc. (Citizenship and Immigration Canada, 2006).

Since members of the couple in arranged marriages tend to have few pre-marital contacts (Bhopal, 1999; Madathil \& Benshoff, 2008; Qureshi, 1991; Stopes-Roe \& Cochrane, 1990) and often have very limited lengths of cohabitation in South Asia before the Canadian marriage partner comes back to file a sponsorship application to facilitate his/her spouse's immigration (Kumar \& Srivastava, 2005), some of these factors may be difficult to assess for arranged relationships. However, the issue of presentation of the spouses as a couple to friends and their cultural communities may be of prime importance. If the cultural community of which members of a couple are a part would not likely recognize such marriages due to their divergence from established cultural norms related to mate selection, this may suggest possible immigration fraud. This may be the case even if members of a couple suggest that they do present themselves as a couple in their immigration interviews.

The purpose of this study was to uncover the most salient norms related to mate selection and marriage among South Asians that can inform immigration fraud detection, taking into account withingroup diversity in religion and subculture. The aim was to obtain information from cultural "insiders" from the different groups within the South Asian community in Canada, as well as those who have worked with immigration fraud cases in international arranged marriages to draw on their expertise in understanding how cultural norms may express themselves in genuine versus fraudulent relationships. Results could inform cultural education for immigration officers, as well as key areas of inquiry for them to pursue in the relationship assessment for marriage-based immigration applications.

\section{Participants}

\section{Method}

Recruitment process. Focus groups were conducted in major metropolitan centers in the 3 provinces with the largest South Asian immigrant populations in Canada. One focus group was held in each region with 7 to 10 members: Ontario (held in Toronto), British Columbia (held in Vancouver), and Alberta (held in Edmonton). Focus group participants for each region were identified through initial consult with the research collaborator in the National Indo-Canadian Council based on two criteria: (a) knowledge of South Asian cultural norms surrounding marriage and mate selection; and (b) active community involvement in relation to marriage-based immigration fraud through: Legal or social advocacy, or community support provision. The second criterion would ensure that they could speak meaningfully from their direct experience about how marriage norms relate to immigration fraud situations to shed light on how to improve fraud detection while respecting culturally-sanctioned marriage practices. A concerted attempt was made to include religious and community association leaders from each subgroup of the South Asian community in the sample to acknowledge within-group diversity. Initial recruitment contacts were followed by "snowball" sampling: individuals/leaders contacted to consider voluntary focus group participation to share their experience/expertise 
subsequently identified and referred other "key informants" to take part in the focus group in their respective region. Potential focus group participants were also recruited through study advertisements within South Asian cultural community organizations and settlement agencies serving large numbers of South Asian clients in the major Canadian cities where the study was taking place.

\section{Participant characteristics.}

There were 27 participants across the 3 focus groups conducted ( 2 focus groups included 10 members, and 1 included 7 members). Of these participants, 19 were female, and 8 were male. Twenty-four of the 27 were members of the South Asian community (Hindu, Muslim or Sikh self-identification from India or Pakistan), whereas 3 were Caucasian Canadians serving the South Asian community in either legal or social work roles. The participants' ages ranged from 26 to 75 years. They were engaged in various community and employment roles that provided them with direct knowledge of South Asian marriage norms, as well as direct experience working with marriage fraud victims to see how marriage norms or violations of them play out in fraud situations.

Five participants were leaders of cultural community associations for the Hindu, Sikh, and Muslim communities. Three participants were members of the clergy (e.g., religious leader from Sikh Gurudwara, representative from Hindu Temple, Imam from Muslim Mosque). Six were Executive Directors of settlement agencies serving a large proportion of South Asian immigrant clients or exclusively South Asian clients. Four participants were immigration lawyers in South Asian legal clinics or mainstream law firms who had represented South Asian Canadians in litigation related to marriage fraud cases (e.g., seeking deportation orders of the foreign spouse). Two were leaders/board members of national immigration fraud victim advocacy organizations. The remaining 7 focus group participants were frontline workers, including South Asian outreach workers, settlement counselors, and social workers working with members of their own communities in community agencies, mental health clinics, or cultural associations.

\section{Data Collection}

Focus groups were conducted to seek insider input from the research participants about cultural norms surrounding marriage and mate selection for the various subgroups of the South Asian community that outsiders may not be aware of, and that would be critical for differentiating between genuine marriages and marriages of convenience for immigration. Focus groups were scheduled for 3 hour blocks in boardrooms at conveniently located South Asian cultural organizations/settlement agencies in the major Canadian cities where they took place. The focus groups were facilitated in English by the researcher, since all of the religious and community leaders, advocates, and legal and helping professionals serving the South Asian community were bilingual. The researcher began the dialogue with the participants by inviting them to talk about arranged marriage practices in the South Asian culture and the different forms they take. Subsequently, they were asked to discuss cultural norms surrounding marriage and mate selection across South Asians and within particular subgroups of the community based on cultural, religious, or regional differences. Specific examples of subculture norms were also solicited. Focus group participants were directly asked about how any norms described relate to attempts to detect marriage-based immigration fraud, while respecting genuine marriages based on adherence to South Asian cultural traditions.

\section{Data Analysis}

All focus group dialogues were audio-taped on digital recorders and transcribed verbatim by the study research assistant, who was a graduate student of South Asian descent. Focus group transcripts were analyzed using interpretive phenomenological analysis (Smith, Flowers, \& Osborn, 1997). This 
procedure involves carefully reviewing transcripts and excerpting salient or repeated ideas expressed by each participant about perspectives and insider cultural views on the topic at hand. Subsequently, a cross-participant analysis is conducted to search for shared insights, perspectives, or views. Then the researcher attempts to generate organizing categories or themes representing specific cultural norms and exemplars under which focus group participants' comments and descriptions can be subsumed. The categories are then labeled in a way that reflects their meaning according to the participants' expertise. In the presentation of study results that follows, focus group participants' insider insights are revealed to identify key community patterns of marriage and mate selection, as well as their relevance for fraud detection.

\section{Emerging Themes}

Focus group participants emphasized that understanding community and cultural norms is essential for recognizing genuine arranged marriages and detecting immigration fraud. They also highlighted the significant polarity in subculture marriage norms among South Asians based on regional differences, religious groupings, and cultural identification. Three key themes emerged from an analysis of their disclosures and dialogues: (a) "All in the Family" - Intra-familial Marriage Patterns, (b) "The Family is Out" - Extra-familial Marriage Patterns, and (c) Exceptions to Every Rule. Each of these themes is described below, along with supporting quotes from focus group participants' disclosures.

\section{Theme One: "All in the Family" - Intra-familial Marriage Patterns}

Focus group participants explained that there are some subgroups within the South Asian diaspora that practice intra-familial marriages, with specific patterns of mate selection between families being pre-defined. They talked out how such practices occur among members of the South Asian community from particular geographic regions and particular religious subgroups, and emphasized how important it is to recognize these genuine practices since they are both culturally and socially sanctioned. A focus group member explained:

In South India, marriage takes place between maternal uncle and niece. They will say we are not cousins and the relation between maternal uncle and niece is not close enough to be considered incestuous, so these marriages are culturally accepted and normal. They allow people to marry within families to people they know and care about in a way that is socially sanctioned by the community there.

Another focus group member cautioned: "You don't see this practice in Northern India though. There it would be incest, so immigration officers have to know the difference." He elaborated:

If a person living in Canada wanted to sponsor a husband or wife from North India and that person was his/her niece or maternal uncle, respectively, then that is a situation where both family members are likely entering a marriage of convenience for family chain immigration, which would eventually be followed by divorce.

Other focus group members described the common practice of first cousin marriages among Muslims from the Pakistan region, which are not practiced by Muslims from other regions. One participant stated: "First cousin marriages are common among some South Asian groups, such as the Pakistani Muslims". Another shared "these marriages can be to a first cousin from either the mother or father's side, and there may be limited interaction between them before marriage if one has been living abroad and one has stayed in Pakistan." A third focus group member outlined how this plays out through the Pakistani tradition of telephone marriages: "The marriages from Pakistan, they are predominately Muslim marriages. Indians living in Canada, they go there physically and get married, but in Pakistan it's over the phone". She further explained:

Telephone marriages are very common - the Canadian marriage partner is on the phone here, the cousin is on the phone back home, and there is a religious officiator and lawyer there in Pakistan 
to witness the marriage and to have legal papers signed and faxed to both parties. Then the Canadian partner goes abroad to see the spouse and comes back to file a sponsorship application to bring his/her new partner back to Canada. Since the families know each other by direct relation, it is considered fully authentic and legitimate.

Other focus group members highlighted the importance of understanding within-group diversity among South Asians in relation to these subculture norms. One remarked: "However, these cousin marriages are not practiced by the Hindu and Sikh communities". Another expanded: "So if Hindus or Sikhs are sponsoring first cousins as spouses something is likely wrong and it is a fraud situation that should raise a red flag of families trying to immigrate their members."

\section{Theme Two: "The Family is Out" - Extra-familial Marriage Patterns}

In contrast to the intra-familial marriage practices described in the first theme, focus group participants explained that Hindus actively refrain from marrying members of their own families, not only first-degree biological relatives, but those with relations going many generations back. They talked about how Sikhs take this distancing process even further by avoiding marriage with any individuals who are from the same village in the Punjab as their village of origin. Quotes related to Hindu marriage practices are provided first, followed by quotes related to Sikh marriages.

A focus group member shared: "Scientifically and according to Hindu law, the difference from the father's side should be five generations and from the mother's side four, so a four-generation gap and then they can get married." He further commented: "This is because of genetics". Another member concurred, stating "If you are Hindu.... by far and large, you do not marry from any one related up to 4 generations of your mother's Goth [lineage]." A third focus group participant elaborated, saying "to do so would be considered incest and against the culture and beliefs".

Other focus group members explained village-related marriage practices among Sikhs from the Punjab region of India. "There's cultural norms, and Sikh people from Punjab will most likely be marrying someone from another village in Punjab". It was explained: "In the village, there are different castes. Some are trades people, some general labor, and third is Brahmin or upper caste. These castes try to marry within caste but don't get their children married within the same village." A focus group member shed more light on the reasons for this reluctance to marry within the same village:

In the past, it used to be that they'd look at four family generations of family names or lineage then boy's, girl's family name shouldn't be same - lets say his mom and her mom should not have same last name or family name....But, since villages are close knit, there is assuming some in-breeding that can't factor everything out by names, that's why you have to marry someone outside of your village in the Punjab.

Participants talked about the relevance of such marriage traditions for detection of immigration fraud in transnational arranged marriages: "So if someone living in Canada who comes from a specific village in the Punjab is sponsoring a husband or wife from the same village, it is suspect." They cautioned: But these rules don't apply to people living in cities in the India, like Delhi or Mumbai, as they are so large that no in-breeding is suspected in such major overpopulated centres. So immigration officers need to know the difference between marriage norms among villagers and among citydwellers even of the same Sikh backgrounds.

\section{Theme Three: "Yes, but..." - Exceptions to Every Rule}

Focus group participants highlighted the challenges that occur if we see cultural norms as inflexible, because they have exceptions. Interestingly enough, they talked about how the exceptions stem from the collectivist or family-oriented nature of the overall South Asian culture, where concern for family members' welfare may lead people to sometimes break the rules around standard marriage practices. The consensus among focus group participants was that rules are often broken in relation to 
arranging re-marriages for widows, so immigration officers should keep this in mind in evaluating international arranged marriage cases. They also spoke about how marriages between members of different South Asian subgroups, such as Hindus and Sikhs or Sikhs and Muslims represent exceptions. Related quotes are provided below:

We say how come the visa officers do not know - but it is very hard to find. Sikhs never marry first cousins. Yes, but now I'm going to be self-defeating because there are exceptions.... Usually there is no incest in the marriage and you will not marry relatives except on sympathetic ground. For example, a young girl, the husband dies - the family will marry her to the younger brother to keep her in the family. Normally this is absolutely no, but in this case just to help the girl, the community will sanction the marriage.

Similarly in cousins...For example, if there is a widow and she has an unmarried male cousin in her family, then he will understand her situation and they will marry first cousins in the Hindu community. This will be done only to care for the girl and to keep the property within the family, so there is an economic motive as well as a care-giving motive at the family level.

One focus group participant summed it all up saying: "There are circumstances where it may seem No, this is against the cultural norms for that South Asian subgroup - but it may be alright in the care of widows by a family."

In discussing inter-group marriages, focus group participants talked about how although these are not socially sanctioned by the members of each South Asian cultural subgroup and there is a strong preference to marry within one's own cultural and religious grouping, they are becoming more common. Furthermore, since such marriages take place across cultural boundaries, the within-group marriage norms don't apply when marital partners vary in cultural, religious, or regional backgrounds. As a focus group member explained: “Generally, people don't approve of intergroup marriages and parents often severely punish kids who enter into such relationships or try to force them into marriages to people of their choosing, but some young people are able to resist these days." Another participant shared: "In mixed marriages, the rules of either subculture can't be applied, because two groups are blending." The final comment on this topic was that:

Immigration officers need to assess the religious, cultural and regional background of each member of the couple to see if they match or not....if they match, then they have to check if the marriage conforms to cultural norms and if not, is it due to a widow situation? If the backgrounds don't match, then the norms of each subculture don't necessarily apply.

\section{Discussion}

International arranged marriages are increasing in frequency (Citizenship and Immigration Canada, 2012a;), and one of the primary reasons for seeking partners from abroad relates to a desire for cultural traditionalism in one's spouse (Constable, 2003, 2005, Raj \& Silverman, 2002). South Asians are an immigrant group whose desire for cultural traditionalism and maintenance has resulted in the application of their custom of arranged marriages across international borders. Arranged marriages are differentiated from non-arranged marriages by the expectation that love will develop between the partners after they get married, so extensive pre-marital contact or prior affectional bonds between members of the couple are not required or typical (Almeida, 1996; Assanand et al., 1990; Bhopal, 1999; Qureshi, 1991; Stopes-Roe \& Cochrane, 1990). Therefore, the assessment of the genuineness of these marriages cannot easily be based on standard factors evaluated in adjudication of spousal immigration applications based on Western marriages. These factors include frequency of premarital interaction and communication, physical, emotional, financial, and social interdependence as evidenced by actions such as cohabitation or combining personal affairs and bank accounts, presentation of partners to others as a couple, and level of knowledge of each other and each other's families (Citizenship and Immigration Canada, 2006). Respect of authentic international arranged 
marriages among members of this group and detection of fraudulent marriages for immigration requires immigration officers to have insider knowledge about norms for mate selection practiced among the various South Asian subcultures.

The findings of this study highlighted some of the key types of information that they would need to be provided with in cultural education sessions about the marriage norms among South Asians. It is clear from the study results that it would be erroneous to consider the South Asians as a homogenous group; their marriage and mate selection practices suggest significant within-group diversity. Previous research has also identified South Asians as a group with a unifying cultural worldview but marked heterogeneity in religion and application of cultural traditions (Almeida, 1996; Assanand et al., 1990; Ballard, 1982; Bhopal, 1999; Qureshi, 1991; Stopes-Roe \& Cochrane, 1990). The research results suggested that two primary subtypes of international arranged marriages are practiced among the South Asian diaspora: (a) intra-familial marriages and (b) extra-familial marriages, each with variations in their application depending on the geographic locale of origin of a South Asian family or their religious or cultural subgroup. Cultural insiders in this study indicated that intra-familial marriages are practiced among Muslims from Pakistan and those of the South India region. The familybased marriages of Muslims from Pakistan focus on uniting first cousins, whereas South Indian marriage practices involve marriage of nieces to their maternal uncles. Anthropologists and social geographers studying South Asian culture have corroborated these subculture marriage practices in their research studies (Ballard, 1982; Pande, 2014). However it is important to note that such marriages would be considered incestuous by the other South Asian religious and cultural subgroups, and even those defined by geographic region (e.g., North Indians). When members of other groups show such marriage patterns, this would suggest immigration fraud potential.

Extra-familial marriage patterns discovered in this research study relate to Sikh traditions of avoiding genetic mutations associated with marrying relatives by marrying people outside of one's village, and Hindu traditions emphasizing avoidance of marriage to anyone within 4 generations of one's mother's lineage (and often the father's lineage as well). The Sikh belief is that villages tend to often consist of members that have some level of blood ties, thus increasing the risk of incest if marrying within one's own village. Ballard (1982) explains that Hindus and Sikhs marry outside of their family lineage but within their social castes, and that social caste is a key factor in determining whether group members will socially sanction a specific marriage. In light of this pattern of cultural norms, marriage partners in international unions of these subgroups who either originate from the same village or have similar heritage and last names from their mother's, father's, or grandparents' sides of the family would thus raise a red flag for immigration fraud.

Interestingly, it appeared that cultural norms surrounding marriage and mate selection across the various South Asian subgroups could be overturned for the second marriages of widows. Focus group members who were cultural insiders rationalized such marriages on "compassionate grounds", where members of groups practicing extra-familial marriage would take over the care for a widowed family member. Researchers coming from the legal field provide an alternative perspective and refer to this pattern of behavior as wife inheritance: A situation where a brother-in-law inherits the privilege of marrying his diseased brother's bride (Seelinger, 2010). Seelinger (2010) postulates that re-marriages of widows to other members of their husband's families may be forced marriages that are not necessarily in the best interests of the women's well-being.

Focus group members also identified intergroup marriages as being exempt from cultural norms applied to within group marriages, due to the mixing of cultures, religions, or regional practices. It was surmised that those entering intergroup marriages would have to withstand significant pressure against the marriage, ostracism, and even abuse or threats, increasing the likelihood that such marriages are genuine. In a study of attitudes towards intergroup dating and marital relations, Uskul, Lalonde, and 
Konanur (2011) found that South Asian adults viewed such interactions much less favourably than their European-Canadian counterparts, suggesting low levels of approval of mates from other groups.

The marriage patterns above that emerged from this study can be better understood by considering prevailing theoretical frameworks on the construct of culture. In synthesizing several theories of culture and related research findings to arrive at a meta-theory about what culture is and how it operates, Matsumoto (2000) described culture as "a dynamic system of rules, explicit and implicit, established by groups in order to ensure their survival, involving attitudes, values, beliefs, norms, and behaviours, shared by a group, but harbored differently by each specific unit within the group, communicated across generations, relatively stable, but with the potential to change across time" (p. 24). The work of anthropologists, Harris and Johnson (2000) expands this conceptualization by relating culture to a society's infrastructure, structure, and superstructure. Infrastructure refers to the way members of a group in a society obtain food and shelter, maintain their population, and attend to their basic biological and emotional needs. A society's structure is comprised of both its domestic economy and political economy. Domestic economy refers to social organization (often according to gender, age, and social class), kinship ties, and division of labour, whereas political economy refers to social hierarchies and political institutions among or within groups in the society. In contrast to the structure, the superstructure of a society refers to the ideological, religious and symbolic aspects of culture that permeate everyday life. All aspects of society and culture are assumed to be interdependent. People are active creators of culture as they propagate and maintain its existence through gender role socialization and transmission of ways of life across generations, emphasizing appropriate and inappropriate behaviors for males and females, clearly defining in-group and out-group boundaries, and applying related social sanctions (Harris, 2001; Harris \& Johnson, 2000).

Matsumoto's (2000) description of culture captures the within-group diversity among the South Asian diaspora and the related variability in accepted marriage and mate selection norms based on geographic location and religious beliefs, the latter of which would comprise the superstructure of this diaspora. The multi-generational transmission and application of the marriage norms found in this study also implicates a strong domestic economy that has persisted across time likely due to some of its essential functions in maintaining group members' survival and viability. For example, extra-familial marriage norms would minimize the risk of genetic problems in offspring, whereas the marriage of nieces to maternal uncles were rationalized by in-group members as ensuring adequate care to young women by people within the family who already love them, thus being viewed by the group to reduce the risk of abuse. The collectivist nature of the social organization among the various South Asian cultural subgroups also makes it unsurprising that the primary circumstances for departure from existing marriage norms relate to caring for family members who have lost their primary supports due to spousal death.

\section{Implications}

The results of this study have important implications for the education and training of Citizenship and Immigration Canada Visa officers in relation to conducting a culturally-appropriate and relevant relationship authenticity assessment when evaluating spousal sponsorship applications based on international arranged marriages among members of the South Asian community. The major factors in the assessment are geared towards determining whether a marriage is genuine or fraudulent (Citizenship and Immigration Canada, 2006). Given that the application of subculture norms for marriage and mate selection may vary depending on whether it is a person's first marriage or second marriage, and also based on whether it is a within group marriage versus an intergroup marriage, initial areas of inquiry in the assessment process should address these two critical issues. If the marriage is a first marriage for both partners, it then needs to be determined whether the partners are from the same cultural or religious group within the South Asian diaspora. If they are members of the same group, e.g., 
both are Muslims or both are Hindus, then the inquiry process should move to consider whether they are from the same geographic region of South Asia, taking into account whether their geographic regions of origin are villages or major cities. The insider information obtained in this study suggested that if both marital partners are Sikhs and they originate from the same village, the marriage could be fraudulent. If both partners are Hindu, whether their surnames match or differ for their own generation, their parents and their grandparents' generations becomes an important factor in detection of marriagebased immigration fraud, as people will marry outside of their family lineage. Social caste of members of the couple should also be determined from their own perspectives. If members of the couple are both Muslims, and a relative is being married, the nature of the family relation needs to be assessed, as first cousin marriages are common among Pakistani Muslims. However, if family members are presenting as a couple for immigration, the pattern among South Indians would be for a niece to marry her maternal uncle, rather than a cousin. In contrast, North Indians would consider such relations incestuous and would not genuinely propose such marriages.

Based on the study results, if the marriage being assessed is a second marriage and the woman is a widow, even if the cultural/religious group the partners are from doesn't usually support intrafamilial marriage, marriage of the woman to a sibling of the diseased spouse or to a first cousin could be considered legitimate on compassionate grounds. So inquiries should focus on the specific family member the woman is being married to and the family's rationale for accepting such a remarriage despite existing subculture norms that go against it. A final implication of this study for the relationship authenticity assessment in international arranged marriages is that for intergroup marriages, cultural insiders suggested that none of the other within-group cultural norms can be reasonably applied. Therefore, assessors need to keep in mind that the marriage is more likely to be genuine as the couple would have had to withstand significant pressure from family members to marry within the subculture and serious ostracism to stay together. Questions in the assessment process can assess the barriers the couple faced in uniting in marriage to determine relationship genuineness.

\section{Study Evaluation}

This study has two main limitations. First, like all qualitative studies, the results of this research are limited by the small number of participants. However, the concerted attempt to solicit participation from members of various ethnic and religious subgroups within the South Asian community with differing professional and community roles ensured that the resulting sample reflected the heterogeneity of this group. In addition, the recruitment of participants from three different provinces in Canada with the highest proportions of South Asians helped to capture subgroup marriage patterns relevant to the profiles of immigrants from South Asia who have settled in specific parts of Canada. Second, the focus group participant recruitment method involved social networking rather than only study advertisements or other methods that could have yielded a different group of key informants. Pernice (1994) noted the difficulty of accessing the specific segments of immigrant populations needed for research studies without outreach efforts involving members of their cultural communities.

Despite the above limitations, this study met four key criteria for quality control in qualitative research outlined by Stiles (1993): (a) it identified subculture marriage norms based on the collective knowledge and direct experiences of South Asian Canadian insiders in religious, community, and professional leadership positions or community service roles (uncovering), (b) the researcher's collaboration with her South Asian research assistant in generating themes incorporated the multiplicity of perspectives required to establish interpersonal agreement in the data analysis process (consensual validity), (c) the emerging themes resonated with participants' own perspectives on the diversity of community marriage practices (testimonial validity), and (d) the study results enhanced the researcher's understanding of subculture marriage norms relevant to South Asians in international unions. Future research should assess the effectiveness of cultural education on subculture marriage norms among the 
South Asian community and related areas of inquiry for the relationship assessment in improving correct classifications of fraudulent versus genuine marriage cases by immigration officers. 


\section{References}

Almeida, R. (1996). Hindu, Christian, and Muslim families. In M. McGoldrick, J. Giordano, \& J. K. Pearce (Eds.), Ethnicity and family therapy (pp.395-423). New York: Guilford Press.

Assanand, S., Dias, M., Richardson, E., \& Waxler-Morrison, N. (1990). The South Asians. In N. Waxler-Morrison, J. Anderson, \& E. Richardson (Eds.), Cross-cultural caring: A handbook for health professionals (pp. 141-180). Vancouver, BC: UBC Press.

Ballard, R. (1982). South Asian families: Structure and process. In R. Rapaport, M. Fogarty, \& R. Rapaport (Eds.), Families in Britain (pp. 179-204). London: Routledge.

Berry, J. W. (2001). A psychology of immigration. Journal of Social Issues, 57, 615-631.

Berry, J. W. (2006). Contexts of acculturation. In D. L. Sam, \& J. W. Berry (Eds.), The Cambridge handbook of acculturation psychology (pp. 27-42). Cambridge, UK: Cambridge University Press.

Bhopal, K. (1999). South Asian women and arranged marriages in East London. In R. Barot, H. Bradley, \& S. Fenton (Eds.), Ethnicity, gender, and social change (pp. 117-134). New York: St. Martin's Press.

Citizenship and Immigration Canada. (2002). Immigration and Refugee Protection Act. Canada Gazette: Part II, vol. 136 (No. 9).

Citizenship and Immigration Canada. (2006). OP2: Operational Manual for Processing Members of the Family Class. Ottawa, ON: Author.

Citizenship and Immigration Canada. (2011). Summary Report: Consulting the public on marriages of convenience. Retrieved April 4th, 2014 from: http://www.cic.gc.ca/english/department/consultations/marriagefraud/index.asp

Citizenship and Immigration Canada. (2012a). Facts and figures 2012: Immigration overview. Retrieved April $4^{\text {th }}, 2014$ from: http://www.cic.gc.ca/english/resources/statistics/facts2012/permanent/03.asp

Citizenship and Immigration Canada. (2012b). News Release: "The jig is up on marriage fraud" says Minister Kenney. Retrieved December 14 ${ }^{\text {th }}, 2013$ from: http://www.cic.gc.ca/english/department/media/releases/2012/2012-10-26.asp

Citizenship and Immigration Canada. (2012c). News Release- Minister Kenney introduces sponsorship restriction to address marriage fraud \& Regulatory impact analysis statement. Toronto, ON: March 2 $2^{\text {nd }}, 2012$ Press Conference Materials.

Constable, N. (2003). Romance on a global stage: Pen pals, virtual ethnography, and "mail-order" marriages. Berkeley, CA: University of California Press.

Constable, N. (2005). Cross-border marriages: Gender and mobility in transnational Asia. Philadelphia, PA: University of Pennsylvania Press.

Harris, M. (2001). The rise of anthropological theory: A history of theories of culture. Walnut Creek, CA: Altamira Press.

Harris, M., \& Johnson, O. (2000). Cultural anthropology $\left(5^{\text {th }}\right.$ ed). Boston: Allyn \& Bacon.

Ibrahim, F., Ohnishi, H., \& Sandhu, D. S. (1997). Asian American identity development: a culture specific model for South Asian Americans. Journal of Multicultural Counseling and Development, 25, 34-50.

Kumar, N., \& Srivastava, L. (2005). Immigration and arranged marriages. In G. Das (Ed.), International arranged marriages (pp. 82-112). Calgary, AB: Friesen Press.

Kwak, K., \& Berry, J.W. (2001). Generational differences in acculturation among Asian families in Canada: A comparison of Vietnamese, Korean, and East-Indian groups. International Journal of Psychology, 36(3), 152-162. 
Madathil, J., \& Benshoff, J. M. (2008). Importance of marital characteristics and marital satisfaction: A comparison of Asian Indians in arranged marriages and Americans in marriages of choice. The Family Journal: Counseling and Therapy for Couples and Families, 16, 222-230.

Matsumoto, D. (2000). Culture and psychology: People around the world. Belmont, CA: Wadsworth.

Pande, R. (2014). Geographies of marriage and migration: Arranged marriages and South Asians in Britain. Geography Compass, 8(2), 75-86.

Pernice, R. (1994). Methodological issues in research with refugees and immigrants. Professional Psychology, Research \& Practice, 25, 207-213.

Qureshi, R. B. (1991). Marriage strategies among Muslims from South Asia. The American Journal of Islamic Social Sciences, 10 (3), 10-14.

Raj, A., \& Silverman, J. (2002). Violence against immigrant women: The roles of culture, context, and legal immigrant status on intimate partner violence. Violence Against Women, 8, 367-398.

Seelinger, K. T. (2010). Forced marriage and asylum: Perceiving the invisible harm. Columbia Human Rights Law Review, 42, 55-117.

Smith, J.A., Flowers, P., \& Osborn, M. (1997). Interpretive phenomenological analysis and health psychology. In L. Yardley (Ed.), Material discourses and health (pp. 68-91). London: Routledge.

Statistics Canada (2006). Canada's ethnocultural mosaic. Retrieved April 4th, 2014, from:http://cansim2.statcan.ca/cgiwin/cnsmcgi.pgm?Lang=E\&SP_Action=Theme\&SP_ID=30000

Stiles, W. B. (1993). Quality control in qualitative research. Clinical Psychology Review, 13, 593-618.

Stopes-Roe, M., \& Cochrane, R. (1990). Citizens of this country: The Asian British. Clevedon, UK: Multilingual Matters Ltd.

United Nations Population Fund. (2007). Characteristics of sex-ratio imbalance in India and future scenarios. Hyderabad, India: Author.

Uskul, A. K., Lalonde, R. N., \& Konanur, S. (2011). The role of culture in intergenerational value discrepancies regarding intergroup dating. Journal of Cross-Cultural Psychology, 42(7), 11651178.

World Bank. (2012). World Development Report 2102 - Gender and Equality and Development. Washington, DC: Author. 